\title{
ENDOMYOCARDIAL FIBROSIS IN KENYA AND TANGANYIKA AFRICANS
}

\author{
BY \\ PETER P. TURNER AND P. E. C. MANSON-BAHR \\ From King George VI Hospital, Nairobi, and the Provincial Hospital, Nyeri, Kenya \\ Received April 29, 1959
}

In September 1947 at the Sir Albert Cook Jubilee Meeting of the Kampala branch of the B.M.A. Professor Davies read a paper in which he described endocardial fibrosis as a common cause of heart failure in Africans in Uganda. He also paid tribute to Dr. Hennessey and Professor Williams, who had long realized that an odd form of heart disease existed in that country (Davies, 1948). Since then, in an excellent series of papers, the Kampala workers have carefully described the clinical and pathological features of endomyocardial fibrosis and have, so to speak, put this disease on the map (Ball et al., 1954; Williams et al., 1954; and Davies and Ball, 1955).

Independently Bedford and Konstam in 1946 had in a short communication to the British Cardiac Society described the disease in forty young African soldiers, mostly from West Africa. Nwokolo (1955) has, more recently, added a few cases from West Africa. The disease has been described in the Sudan (O'Brien, 1954) and on the Gold Coast (Edington, 1954). In personal communications to Davies and Ball (1955) the disease was said to be seen in Northern Rhodesia and Southern Rhodesia. However, Gelfand (1958) says that the cases he sees are more like those of the nutritional heart disease described by Gillanders (1951) and by Higginson et al. (1952). The description by Becker et al. (1953) of cardiovascular collagenosis in European and Bantu patients from South Africa we find difficult to evaluate, but some of them may have been examples of endomyocardial fibrosis as we know it in East Africa.

What seem to be typical examples of the disease have been described, although in far fewer numbers, particularly in American and Swiss papers, but also in others from France, Germany, Austria, and Britain: possibly those described by Josserand and Gallavardin (1901) were the earliest. The histology of some of the Uganda cases was compared with four from Liverpool and found to be essentially similar (Lynch and Watt, 1957), thus supporting the belief that the same disease entity is under consideration. Occasional cases have been reported in Chinese and Indians in Malaya and Singapore (Shanmugaratnam, 1949; Khaira, 1956; and La Brooy, 1957).

We have been interested in the condition for several years and have submitted all cases dying of heart failure to autopsy, yet have found but few cases. It is difficult to escape the conclusion that the disease is less common in Kenya than in Uganda, and for this we find it difficult to suggest any rational explanation. The purpose of this paper is to present four cases of endomyocardial fibrosis, three of which occurred in Kenya Africans and one in an African from Tanganyika. These are the first cases to be described from these countries, although we believe that one of the Uganda group was a Kikuyu who lived in Kampala.

\section{CASE RePORTS}

The first of our patients was admitted to King George VI Hospital, in August, 1957. He was an adult Mkamba, who had worked for the Public Works Department for some years. His complaints were of headache, abdominal pain, and swelling of the legs. His only previous illness had been pneumonia. $\mathrm{He}$ had signs of severe congestive cardiac failure. His pulse was regular and of low tension. The blood pressure was $96 / 66$ and slight pulsus paradoxus was noted. The heart was considerably enlarged. A systolic apical murmur was heard, but was so soft as to merit little comment. A chest radiograph suggested a pericardial effusion and the clinical diagnosis of tuberculous pericarditis was made, although 
the electrocardiogram (Fig. 1) was that of left ventricular "strain" rather than of pericarditis. There was no eosinophilia. He was treated with streptomycin, I.N.A.H., digoxin, and mersalyl. After two months he had improved and was sent out to continue anti-tuberculous therapy. After a further month he was

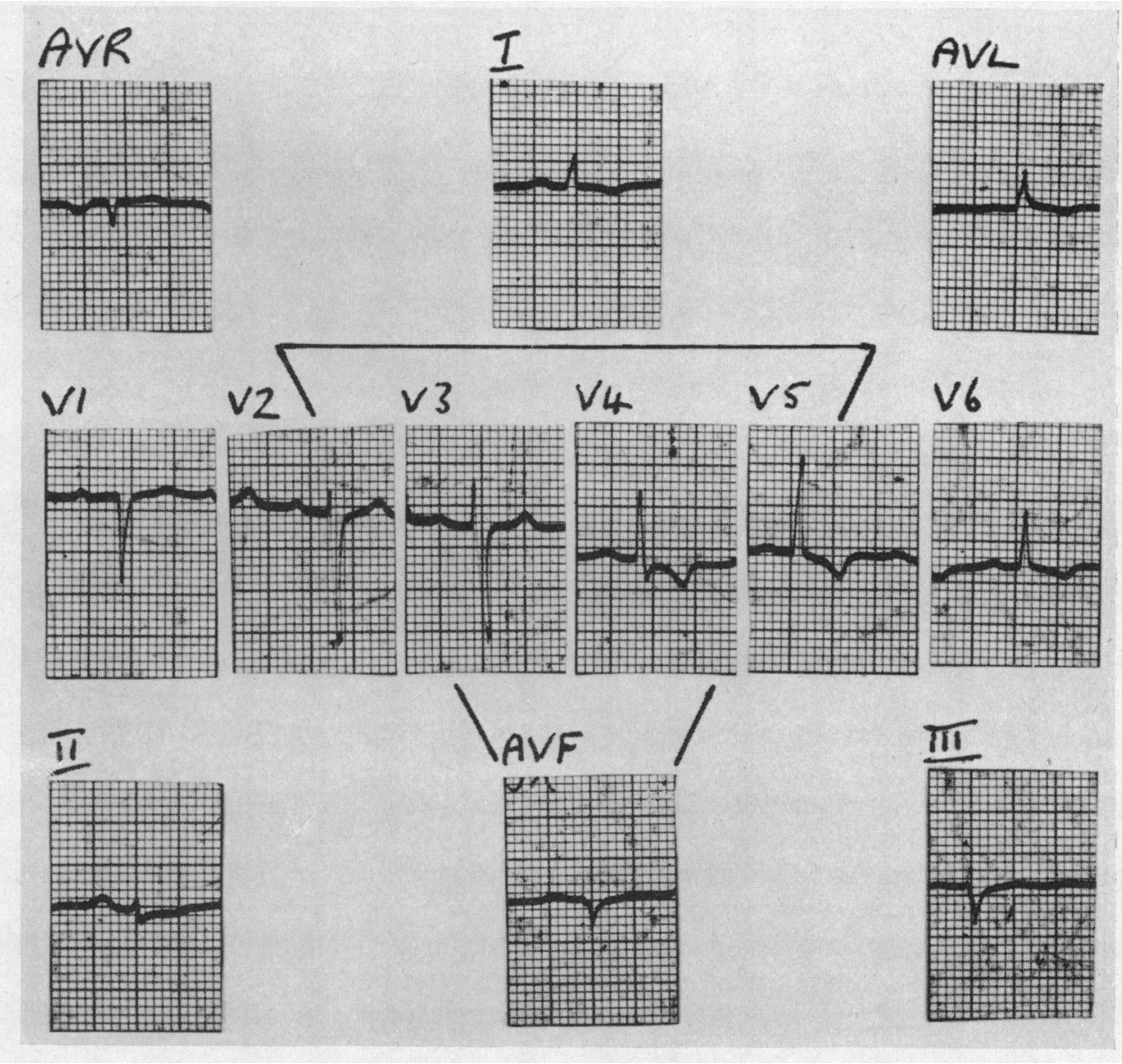

FIG. 1.-Electrocardiogram, showing some left ventricular preponderance (Case 1).

re-admitted with much the same physical signs. Pericardial tapping yielded two pints of blood-stained fluid. Thoracotomy, with a view to removing a constrictive pericardium, was decided upon, but at operation the pericardium was found to be quite normal and so was left undisturbed. He died a week later. At necropsy a blood-stained pericardial effusion was found. There was no pericarditis. The heart was greatly dilated, mostly due to dilatation of the left ventricle. The endocardium of the left ventricle was white and thickened, particularly near the outflow tract, and some adherent thrombus covered it. There was also some ante-mortem thrombus in the right atrial appendage. There were the usual changes of congestive heart failure and sections of the liver showed severe cardiac cirrhosis.

The second of our patients was from Lakeside Tanganyika, where he had worked for many years. He had a massive hæmoptysis and was treated at Musoma Hospital. He took his own discharge but soon began to notice breathlessness on exertion and later abdominal swelling. He decided to go to Nairobi to seek treatment and in April 1958, four months after his symptoms had begun, he was admitted to King George VI Hospital. He was found to be well-nourished, but had signs of moderate congestive cardiac failure. His pulse was regular and of feeble volume. His blood pressure was 116/70 and pulsus alternans was noted. The heart was greatly enlarged and a soft apical systolic murmur and gallop rhythm were heard. The diagnosis of tuberculous pericarditis was suggested, although later endomyocardial fibrosis was 
also considered. The electrocardiogram showed left ventricular "strain". 12 per cent of the 8400 white blood cells were eosinophiles, but the numerous ova of S. Mansoni found in a rectal snip would adequately explain this. He was treated with digoxin and mersalyl, but died within a few weeks. Autopsy showed signs of congestive cardiac failure with ascites and a clear yellow pericardial effusion. The heart was

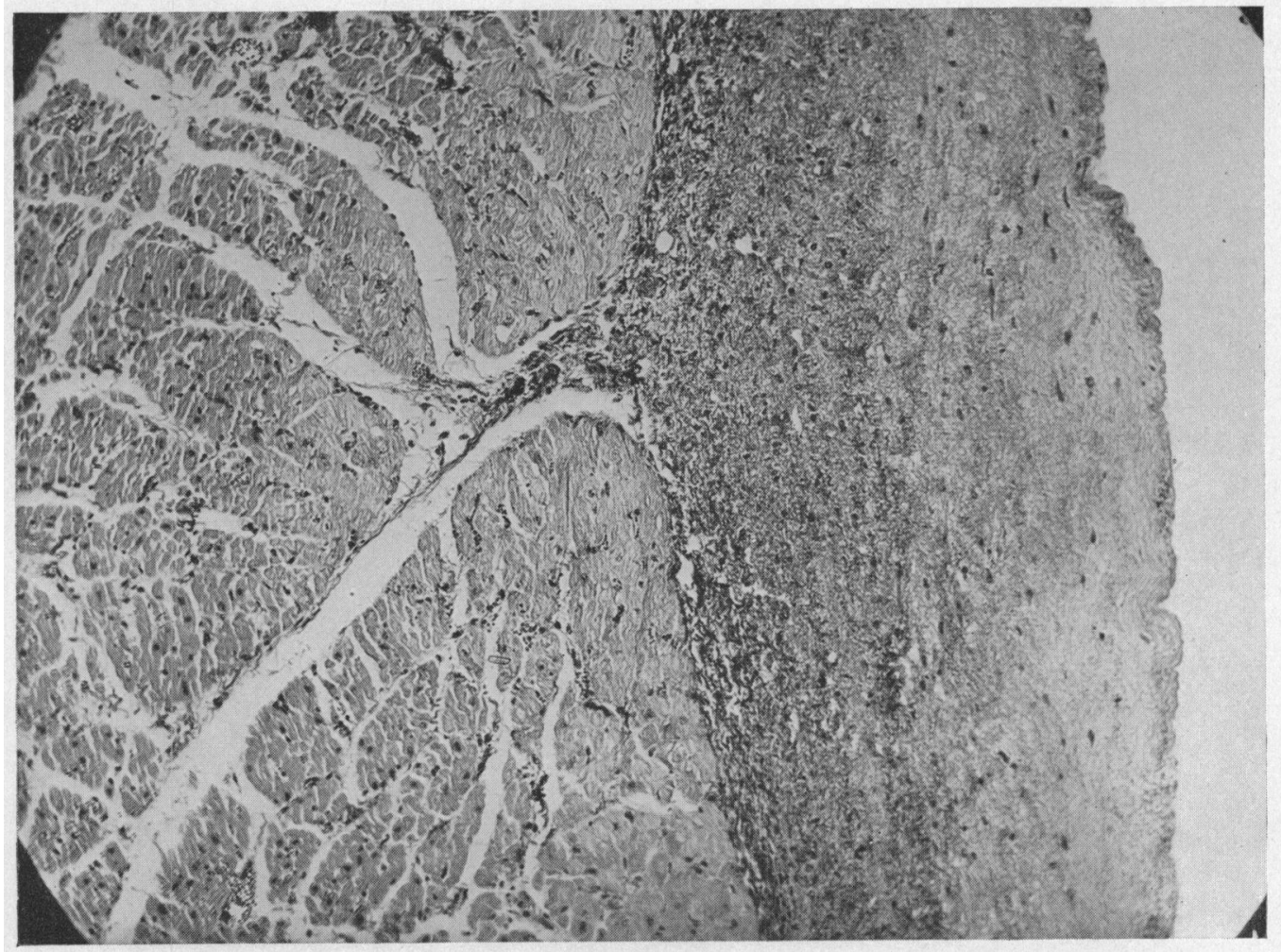

Fig. 2.-Endocardium, showing thick layer of fibrous tissue with infiltration into myocardium (Case 2).

greatly enlarged by dilatation of the left ventricle and atrium. There was a large patch of white and thickened endocardium of the interventricular septum in the left ventricle spreading through to the right ventricle. The chordæ in the left ventricle were involved and had rendered the mitral valve incompetent. There were moderate bilharzial changes in the cæcum. Sections (Fig. 2) showed well-marked endocardial and sub-endocardial fibrosis extending into the myocardium.

Our third patient was a young Meru girl whom we estimated to be about fifteen years of age. She had been seen elsewhere with signs of heart failure which had responded to treatment. A chest X-ray at this time had shown a greatly enlarged heart. Four months later, in April 1958, she was re-admitted and later transferred to our care at Nyeri. She was found to have gross signs of congestive cardiac failure, with regular rhythm, a pulsus paradoxus that was easily felt, and a blood pressure of 90/75. The heart was clinically enlarged; neither murmurs nor added sounds were heard. A chest X-ray showed no change from the one taken earlier. The clinical diagnosis was of tuberculous pericarditis with effusion and cardiac tamponade. A pericardial tap was performed and $240 \mathrm{ml}$. of clear yellow fluid was removed and some $200 \mathrm{ml}$. of air introduced into the pericardial sac. The patient was greatly relieved by this procedure. Radiography (Fig. 3) after this procedure showed the pericardium to be of normal thickness. This, in our experience, is seldom so in tuberculous pericarditis and the diagnosis was, therefore, open to question. The absence of pyrexia and the normal sedimentation rate $(2 \mathrm{~mm}$. in the first hour (Westergren)) made the diagnosis of tuberculous pericarditis even more unlikely and endomyocardial fibrosis was suggested. An electrocardiogram showed low voltage, right axis deviation, depressed RS-T segments in V2 and V4 and a biphasic T wave in V2. There was never any eosinophilia. Digitalis, mersalyl, and the removal of another $360 \mathrm{ml}$. of pericardial fluid helped her temporarily, but one night two weeks after admission, she 
became severely dyspnœic and died. At autopsy there were signs of heart failure with gross ascites and a very large pericardial effusion. There was no pericarditis. There was gross cardiac cirrhosis, which was confirmed histologically. The heart was flabby and dilated, dilatation being chiefly of the right ventricle and atrium. There was a deep depression on the outer border of the right ventricle, which corresponded to the apex of the almost completely obliterated right ventricle. The endocardium in the right ventricle and atrium was a pearly-white colour. The posterior cusp of the tricuspid valve was involved in

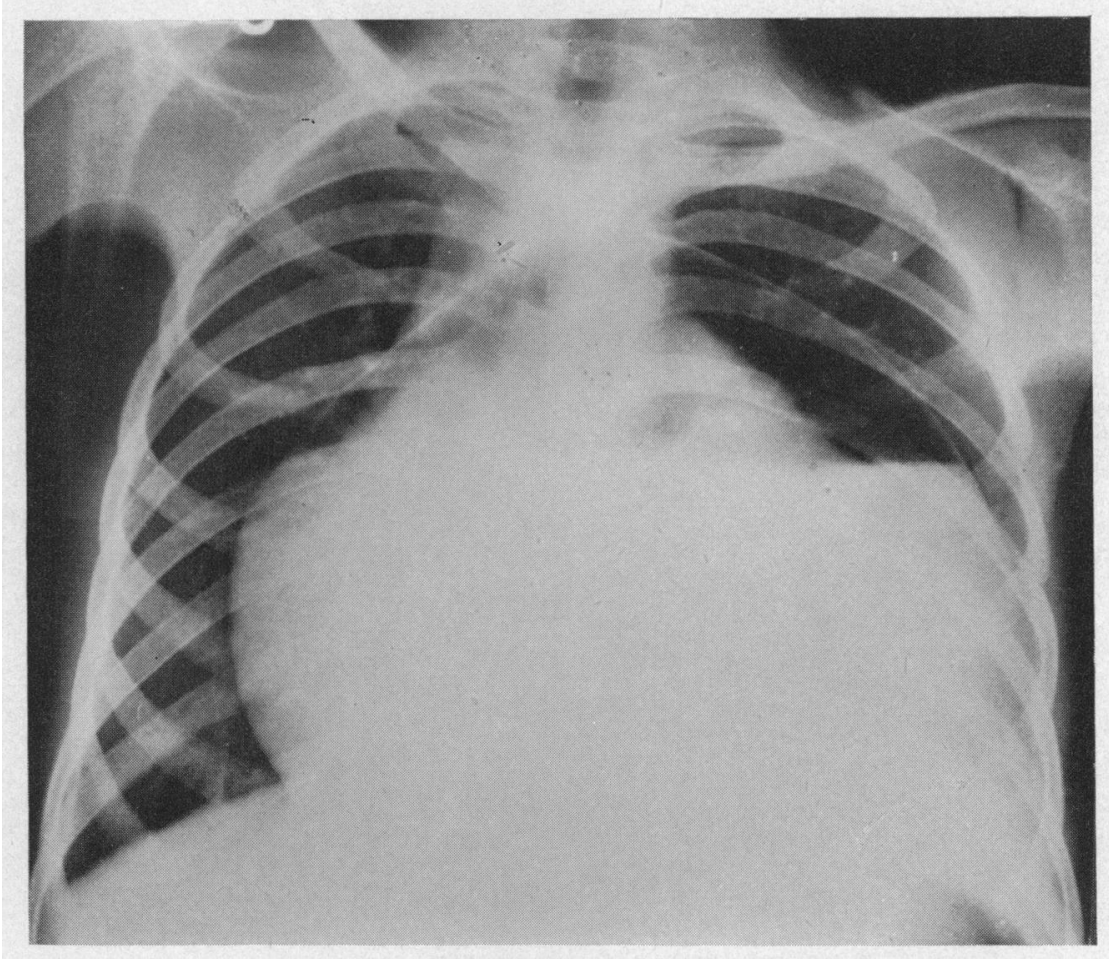

Fig. 3.-Chest X-ray after the introduction of air into the pericardial sac. Note that the pericardium is of normal thickness (Case 3).

the process and thus rendered incompetent. The ventricle contained much old organized thrombus and there was yellow, firmly adherent thrombus in the appendage of the right atrium. Histologically, the picture was typical of endomyocardial fibrosis as seen in Uganda (Fig. 4-7).

Our fourth patient was a Kikuyu man, nineteen years old, admitted to hospital in Nyeri duringAugust, 1958. He had been quite well until the previous day when he awoke with a headache, a swollen face, and breathlessness. On examination he was very dyspnœic and there were mild signs of congestive cardiac failure. The rhythm was regular and the blood pressure was 125/75. Neither cardiac murmurs nor extra sounds were heard. A chest X-ray showed the heart to be little, if at all, enlarged. There were striking shadows suggesting pulmonary œdema. He died suddenly a few days later. At autopsy the lungs were grossly œdematous and there were slight congestive changes in the liver. The heart was of normal size. The left atrial endocardium was thickened and finely rugose, and in the left ventricle there were patches of thickened white endocardium on the interventricular septum extending up to the mitral valve and on to the papillary muscles. Sections showed the typical changes of endomyocardial fibrosis.

\section{Discussion}

The clinical and pathological features of endomyocardial fibrosis have been well described in the several papers from Uganda. Our four cases illustrate some of the ways of presentation and particularly the confusion that can so easily arise with tuberculous pericarditis. Three of these cases were at one time diagnosed as such. This error may occur because a large hydropericardium 


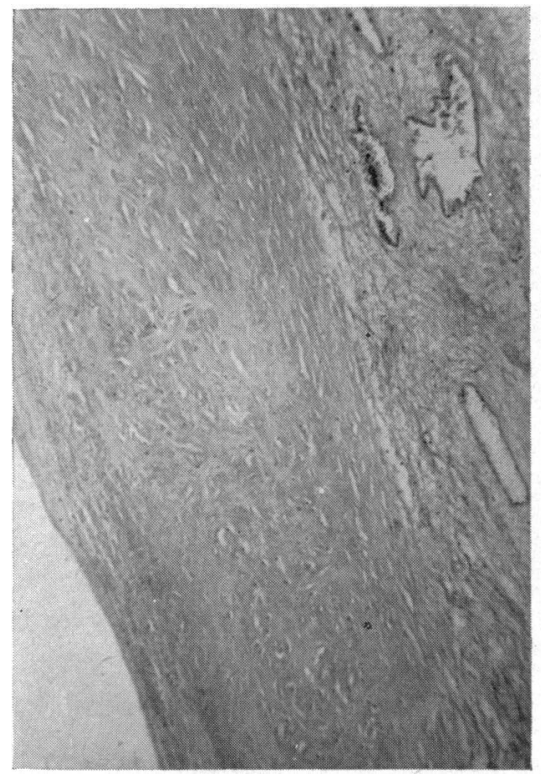

FIG. 4.-Section showing gross fibrosis of the endocardium with dilated venous channels in the deeper layers (Case 3).

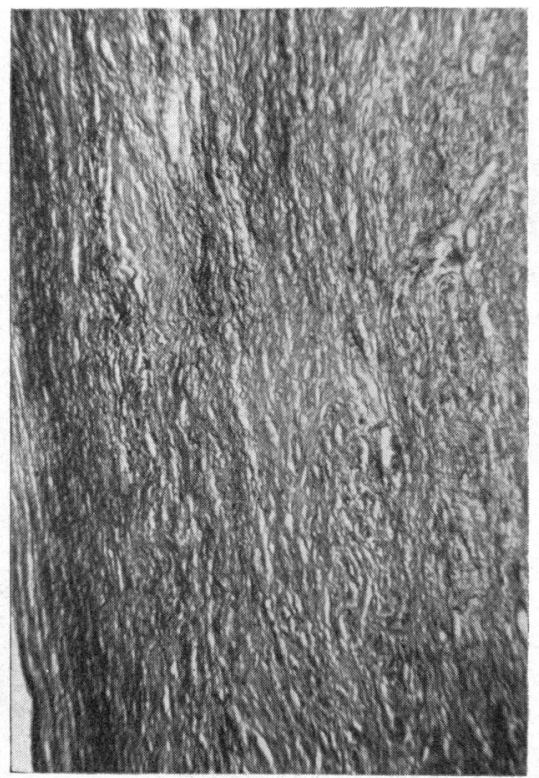

FIG. 6.-Section showing elastosis of the endocardium (Case 3).

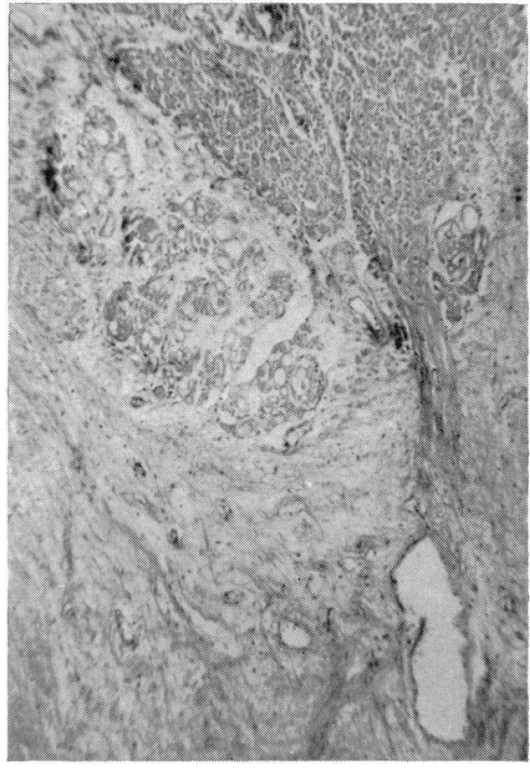

Fig. 5.-Section of the right ventricle, showing the deeper layers of the thickened endocardium with dilated veins and with areas of gross vacuolar degeneration of the myocardium (Case 3).

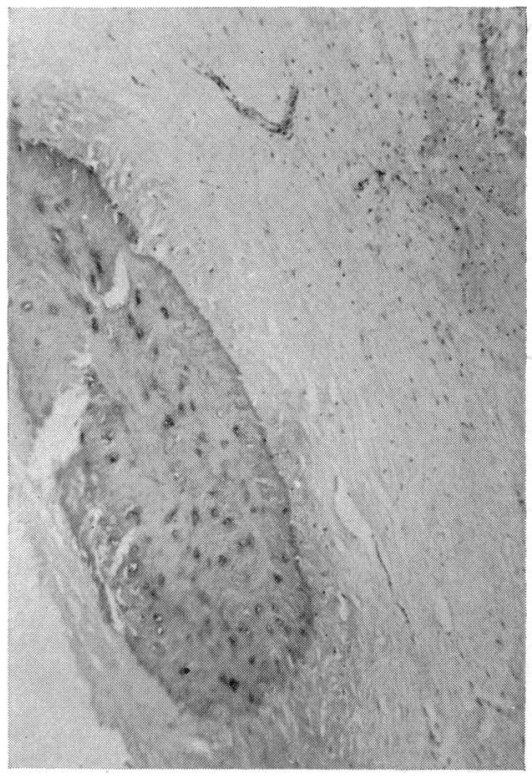

FIG. 7.-An area of calcification in the thickened endocardium (Case 3). 
sometimes complicates this condition or because the clinical picture of the type with an obliterated right ventricular cavity closely resembles that of constrictive pericarditis. That the introduction of air into the pericardial sac may be of diagnostic help is shown in our third case.

The electrocardiographic changes, although non-specific, may also be of assistance. The chest was opened in our first case, yet tuberculous pericarditis was most unlikely with a cardiogram showing such high voltage and such marked left ventricular changes. Voltage of this order is, however, also unusual in endomyocardial fibrosis. The cardiogram of our third patient suggests right ventricular "strain" with an abnormally low voltage, such as was commonly seen by Ball et al. (1954). Wood (1956) states that a hydropericardium produces neither compression nor any electrocardiographic changes. It is interesting that the obliterative right ventricular lesion produces the same mechanical effects as does constrictive pericarditis, even to the extent of an easily appreciated pulsus paradoxus as in our third case. Rigidity of the endocardial surface, if sufficiently severe, could produce the same hæmadynamic changes as does rigidity of the pericardium. However, the condition is more likely to be related to the decreased right ventricular filling capacity, as in the Bernheim syndrome occurring in mitral regurgitation or in hypertension, where the septal wall projects abnormally into the right ventricular cavity and leads to peripheral effects like those of constrictive pericarditis. Much of interest may be learnt when cardiac catheterization studies can be made in endomyocardial fibrosis. Associated with the low voltage cardiogram, the resemblance to contrictive pericarditis could be such that differentiation would be impossible without an exploratory thoracotomy.

The ætiology of the condition remains obscure and we can offer no help in elucidating it. It is of interest that Selye (1958) has produced sub-endocardial necrosis in rats, that on healing gave rise to a condition closely resembling endomyocardial fibrosis. This necrosis was produced by treating them with certain corticoids and sodium salts, and could be prevented by administering magnesium chloride at the same time. Thus, sub-endocardial damage can be produced experimentally and can in healing lead to lesions strikingly similar to those of endomyocardial fibrosis.

\section{SUMMARY}

The widespread occurrence of endomyocardial fibrosis throughout much of the world is emphasized. Its geographical incidence varies considerably. In Kenya, in spite of vigorous search, we have found it to be rare. Four cases are described, one being from Tanganyika and three from Kenya. The differential diagnosis from tuberculous pericarditis may be difficult.

We would like to express our gratitude to Professor Williams and to Professor Davies for their help.

\section{REFERENCES}

Ball, J. D., Davies, J. N. P., and Williams, A. W. (1954). Lancet, 1, 1049.

Becker, B. J. P., Chatgidakis, C. B., and van Lingen, B. (1953). Circulation, 7, 345.

Bedford, D. E., and Konstam, G. L. S. (1946). Brit. Heart. J., 8, 236.

Davies, J. N. P. (1948). E. Afr. med. J., 25, 10 and 476.

-, and Ball, J. D. (1955). Brit. Heart J., 17, 337.

Edington, G. M. (1954). Trans. R. Soc. trop. Med. Hyg., 48, 419.

Gelfand, M. (1958). Central Afric. J. Med., 4, 365.

Gillanders, A. D. (1951). Brit. Heart J., 13, 177.

Higginson, J., Gillanders, A. D., and Murray, J. F. (1952). Brit. Heart J., 14, 213.

Josserand, E., and Gallavardin, L. (1901). Arch. gen. Med., 188, 513.

Khaira, B. S. (1956). Med. J. Malaya, 10, 264.

La Brooy, E. B. (1957). Proc. Alumini Ass. Malaya, 10, 303.

Lynch, J. B., and Watt, J. (1957). Brit. Heart J., 19, 173.

Nwokolo, C. (1955). West Afric. med. J., 4, 103.

O'Brien, W. (1954). Brit. med. J., 2, 899.

Selye, H. (1958). Lancet, 1, 1351.

Shanmugaratnam, K. (1949). Proc. Alumni Ass. King Edw. VII Coll. Med. Singapore, $2,334$.

Wood, P. (1956). Diseases of the Heart and Circulation. London.

Williams, A. W., Ball, J. D., and Davies, J. N. P. (1954). Trans. Roy. Soc. trop. Med. Hyg., $48,290$. 